\title{
Transbronchial Cryobiopsy in Diffuse Parenchymal Lung Disease: Need for Procedural Standardization
}

\author{
Venerino Poletti ${ }^{a, b}$ Jürgen Hetzel ${ }^{c}$ \\ a Department of Respiratory Diseases and Allergology, Aarhus University Hospital, Aarhus, Denmark; \\ ${ }^{b}$ Department of Diseases of the Thorax, Ospedale GB Morgagni, Forli, Italy; ' Division of Pulmonary Medicine, \\ Department of Internal Medicine, University of Tübingen, Tübingen, Germany
}

Transbronchial lung biopsy using regular forceps was and is a common diagnostic technique used in patients with lung infiltrates when, on the basis of clinical background and imaging features, morphological information is deemed necessary to define the diagnosis. This technique is an armamentarium that all bronchoscopists have. and it may contribute to the diagnosis, mainly in cases of peripheral lung tumors or in patients with lesions that have a centrilobular, alveolar and/or perilymphatic distribution [1]. Complications related to this bioptic approach are rare and clinically not relevant in the vast majority of cases (pneumothorax occurs in less than $8 \%$ of cases), although bleeding may in rare cases represent a life-threatening event. The biopsies obtained with these small forceps are infrequently clinically significant when complex histopathologic patterns are the morphological background, such as the usual interstitial pneumonia (UIP) pattern, nonspecific interstitial pneumonia pattern, and other rarer patterns or diseases [2].

Surgical lung biopsy was and is considered the next bioptic method when a regular transbronchial lung biopsy fails. However, the side effects of this invasive procedure are not negligible (pain lasting for months, air leakage, infections or even mortality, mainly due to acute exacerbation of the underlying disorder, in $2-4 \%$ of cases and up to $10 \%$ when DLCO is lower than $50 \%$ predicted) [3-5]. Furthermore, surgical lung biopsy is not worth performing in elderly subjects mainly due to the presence of comorbidities [6].

More recently, cryoprobes used through a flexible bronchoscope have been utilized to obtain lung tissue [710]. The cryosurgical equipment operates by the JouleThomson effect, which dictates that a compressed gas released at high flow rapidly expands and creates a very low temperature. The cooling agent is applied under high pressure through the central canal of the probe (Erbokryo CA; ERBE, Tübingen, Germany). Carbon dioxide $\left(\mathrm{CO}_{2}\right)$ or nitric oxide are the cooling agents commonly used. The gas at the tip expands due to the sudden difference in pressure relative to the atmospheric pressure, resulting in a drop in temperature at the tip of the probe.

The modalities, however, by which this procedure is carried out vary (as reported in the literature since 2009) $[7,10-23]$. The gas more frequently used nowadays (mainly for the presence of specific regulatory rules in the majority of countries hampering the use of nitric oxide in endoscopic suites) is $\mathrm{CO}_{2}$, although nitric oxide may achieve lower temperatures. The ways by which patients are sedated and intubated or even not intubated are different (table 1). The probes used are of different sizes,
Dr. Venerino Poletti

Dipartimento di Malattie dell'Apparato, Ospedale GB Morgagni

Via Carlo Forlanini 34, Pavilion Morgagni IT-47100 Forlì (Italy)

E-Mail venerino.poletti@gmail.com 
Table 1. Transbronchial cryobiopsy for diffuse lung disease: different approaches

\begin{tabular}{|c|c|c|c|c|c|c|c|c|c|c|c|}
\hline First author [Ref.] & Year & OT & $\mathrm{RB}$ & LM & NI & $\mathrm{GA}+\mathrm{JV}$ & GA/DS & LA & $\begin{array}{l}\text { Bronchial } \\
\text { blocker }\end{array}$ & $\begin{array}{l}\text { Cryoprobe } \\
\text { size, mm }\end{array}$ & $\begin{array}{l}\text { Freezing } \\
\text { time, } s\end{array}$ \\
\hline Babiak [10] & 2009 & $\mathrm{x}$ & & & & & $\mathrm{x}$ & & $\mathrm{N}$ & 2.4 & 4 \\
\hline Pajares [11] & 2010 & $\mathrm{x}$ & & & & & $\mathrm{x}$ & & $\mathrm{N}$ & 2.4 & 3 \\
\hline Griff [12] & 2011 & & $\mathrm{x}$ & & $\mathrm{x}$ & & $\mathrm{x}$ & $\mathrm{x}$ & & & \\
\hline Kropski [13] & 2013 & $\mathrm{x}$ & & & & & $\mathrm{x}$ & & & 1.9 & 4 \\
\hline Yarmus [14] & 2013 & & $\mathrm{x}(10)$ & $\mathrm{x}(11)$ & & $\mathrm{x}$ & $\mathrm{x}$ & & $\mathrm{Y}$ & 1.8 & 3 \\
\hline Fruchter [15] & 2013 & & & & $\mathrm{x}$ & & & $\mathrm{x}$ & $\mathrm{N}$ & 2.4 & 4 \\
\hline Fruchter [16] & 2013 & & & & $\mathrm{x}$ & & & $\mathrm{x}$ & $\mathrm{N}$ & 2.4 & 4 \\
\hline Fruchter [17] & 2014 & & & & $\mathrm{x}$ & & & $\mathrm{x}$ & $\mathrm{N}$ & 2.4 & 4 \\
\hline Casoni [18] & 2014 & & $\mathrm{x}$ & & & & $\mathrm{x}$ & & $\mathrm{Y}$ & 2.4 & $5 / 6$ \\
\hline Pajares [19] & 2014 & $\mathrm{x}$ & & & & & $\mathrm{x}$ & & $\mathrm{Y}$ & 2.4 & $3 / 4$ \\
\hline Poletti [7] & 2014 & & $\mathrm{x}$ & & & & $\mathrm{x}$ & & $\mathrm{Y}$ & 2.4 & $5 / 6$ \\
\hline Griff [20] & 2014 & & $\mathrm{x}$ & & $\mathrm{x}$ & & $\mathrm{x}$ & $\mathrm{x}$ & $\mathrm{N}$ & 1.9 & $3 / 5$ \\
\hline Gershman [22] & 2015 & & & & $\mathrm{x}$ & & & $\mathrm{x}$ & $\mathrm{N}$ & 2.4 & 4 \\
\hline Hagmeyer [23] & 2015 & $\mathrm{x}$ & $\mathrm{x}$ & & & $\mathrm{x}$ & & & $\mathrm{N}$ & 2.4 & $4 / 5$ \\
\hline \multicolumn{12}{|l|}{ Hernández- } \\
\hline González [21] & 2015 & $\mathrm{x}$ & & & & & $\mathrm{x}$ & & $\mathrm{Y}$ & 1.9 & $3 / 4$ \\
\hline
\end{tabular}

$\mathrm{OT}=$ Orotracheal tube; $\mathrm{RB}=$ rigid bronchoscope; $\mathrm{LM}=$ laryngeal mask; $\mathrm{NI}=$ no intubation; $\mathrm{GA}=$ general anesthesia; JV = jet ventilation; $\mathrm{DS}=$ deep sedation; $\mathrm{LA}=$ local anesthesia; $\mathrm{Y}=$ yes; $\mathrm{N}=$ no; $\mathrm{x}=$ method used.

and the freezing time (3-6 s; table 1$)$ as well as the distance from the pleura where the freezing process takes place are also reported to be different. The approaches and tools used to control bleeding are again different. Finally, data on the diverse strategies adopted to sample lung tissue (distance from the pleura, number of samples, samples from the same segment, from different segments of the same lobe or even from adjacent lobes) are still missing.

The main debate regards the setting in which transbronchial cryobiopsies are carried out: in sedated and intubated patients or in patients not intubated and under sedation. In the 'non-intubated group', the mean sample size varied from 9 to $17 \mathrm{~mm}^{2}$ and the diagnostic yield from 68 to 100\%, and complications reported were mainly mild bleeding (up to $4 \%$ ) and pneumothorax (maximum $3 \%$ ). In this group, immunocompromised hosts were also included [16].

In the 'intubated group', the mean size of samples varied from 9.5 to $64.2 \mathrm{~mm}^{2}$ and the diagnostic yield from 76 to $91 \%$, and complications reported were pneumothorax $(0-27 \%)$ and severe bleeding (up to 53\%). Studies assessing the pathological agreement between different pathologists for a diagnosis of UIP were done only in the setting of 'intubated patients' [18]. Severe bleeding was described only when a bronchial blocker was not routinely used. In the majority of studies, the larger cryoprobe was utilized $(2.4 \mathrm{~mm})$ [23].

The main point is that transbronchial cryobiopsy should be considered a valid competitor with surgical lung biopsy and not with the regular transbronchial lung biopsy using forceps. With this perspective in mind, the bioptic sample size should be many times greater than that obtained by regular transbronchial biopsy and also representative of the periphery of the secondary pulmonary lobule. These results seem to be achieved better in 'intubated patients' (the bigger sizes were described for the 'intubated group') and when biopsies are taken just $1 \mathrm{~cm}$ from the pleura $[8,18]$. Weight and diameter of cryobiopsies correlate positively with longer activation times and larger diameters of the cryoprobe [24, 25]. Concerning the dependency on freezing time, a significant increase in biopsy weight was observed after $3 \mathrm{~s}$ with the 1.9-mm cryoprobe compared with a freezing time of $2 \mathrm{~s}$, and after $2 \mathrm{~s}$ with the $2.4-\mathrm{mm}$ probe compared with a freezing time of $1 \mathrm{~s}$. In the studies published so far, the sample size appears to be bigger when larger cryoprobes or a freezing time $>4 \mathrm{~s}$ are used. Patients intubated with an orotracheal tube or even rigid tracheoscopes do not need supports for ventilation, although in some centers jet ventilation is used when rigid tools are adopted. Routine use of a bronchial blocker (Fogarty balloon or an- 
Table 2. Comparison between different transbronchial cryobiopsy modalities

\begin{tabular}{lllll}
\hline & $\begin{array}{l}\text { Intubation } \\
\text { with OT }\end{array}$ & $\begin{array}{l}\text { Intubation } \\
\text { with RT }\end{array}$ & LM & NI \\
\hline Need of GA/DS & $\mathrm{Y}$ & $\mathrm{Y}$ & $\mathrm{Y}$ & $\mathrm{N}$ \\
Control of bleeding & $\mathrm{Y}$ & $\mathrm{Y}$ & $\mathrm{Y} / \mathrm{N}$ & $\mathrm{N}$ \\
Size of specimens & +++ & +++ & + & + \\
Size of OF & ++ & +++ & + & - \\
Comfort for patients & +++ & +++ & +++ & - \\
Technical effort & ++ & +++ & + & - \\
\hline
\end{tabular}

$\mathrm{OT}=$ Orotracheal tube $\mathrm{RT}=$ rigid tracheoscope; $\mathrm{LM}=$ laryngeal mask; NI = no intubation; GA = general anesthesia; DS = deep sedation; $\mathrm{OF}=$ operating field; $\mathrm{Y}=$ yes; $\mathrm{N}=$ no.

other blocker) should be made only in intubated patients or in patients with a laryngeal mask, and it appears to prevent the potentially dangerous effects of major bleeding $[8,18,23]$. The rate of pneumothorax varies in different series, and it seems to be significantly higher when the biopsies are obtained just beneath the pleura or in subjects with the UIP pattern (a higher pneumothorax rate of $28 \%$ was reported by Casoni et al. [18], but in this study the biopsies were obtained a maximum of $1 \mathrm{~cm}$ from the pleura and the samples showed a UIP pattern in $75 \%$ of cases). Differences between intubation using orotracheal tubes and rigid tracheoscopes appear irrelevant, although the use of tracheoscopes might allow pulmonologists to handle instruments in larger 'operating fields' as the ventilatory supports are very similar.

The strategies used to collect samples are also different. The distance between the point of resistance (considered to be the point nearest to the visceral pleura) and the site in which the probes are frozen varies from $2 \mathrm{~cm}$ to less than $1 \mathrm{~cm}$. One study [18] reported good pathologic interobserver variability (similar to that observed in surgical lung biopsy specimens) in recognition of the UIP pattern when the biopsies were obtained less than $1 \mathrm{~cm}$ from the pleura, suggesting that this approach is valuable in order to identify this complex morphological pattern. The majority of studies reported retrieving lung tissue from one segment, and only a minority collected lung samples from different segments of the same lobe. No prospective studies have been published yet comparing these two approaches in terms of diagnostic yield and rates of complications. Even less information is available on biopsies performed in different ipsilateral lobes, although this approach seems to be reasonable in cases in which the CT scan pattern differs greatly between different lobes (i.e. pleuroparenchymal fibroelastosis with lower-lobe 'fibrosis').

The procedural standard of transbronchial cryobiopsy in diffuse parenchymal lung disease is not yet homogeneous. In table 2, the strengths and weaknesses of the different approaches are summarized. It appears that intubation and utilization of general anesthesia or deep sedation have advantages: the control of severe bleeding is easier, and the larger 'operating field' allows the use of different tools without stopping the procedure (radial echographic probes, additional aspiration tubes, etc.). Rigid tubes, being larger and not bended, are the best choice in this context. However, when using rigid tubes, general anesthesia is mandatory, and the technical effort required is higher. Furthermore, because after any sampling the flexible bronchoscope needs to be removed, intubation is more comfortable for the patients. Regarding the probes, the $2.4-\mathrm{mm}$ size appears to provide larger samples mainly when the freezing time exceeds $4 \mathrm{~s}(5 / 6 \mathrm{~s}$ is the freezing time used at the Morgagni Hospital and at the Tübingen University Hospital).

Finally, new prospective studies comparing the different strategies adopted to sample the lung parenchyma are needed in order to assess if the diagnostic yield, mainly in complex morphological patterns such as UIP, is higher if the biopsies are obtained just beneath the pleura or about $2 \mathrm{~cm}$ away when different parts of the lung are sampled, and also to assess the minimum number of samples necessary to obtain a diagnosis.

References

Poletti V, Chilosi M, Olivieri D: Diagnostic invasive procedures in diffuse infiltrative lung diseases. Respiration 2004;71:107-119.

-2 Tomassetti S, Cavazza A, Colby TV, Ryu JH, Nanni O, Scarpi E, Tantalocco P, Buccioli M, Dubini A, Piciucchi S, Ravaglia C, Gurioli C, Casoni GL, Gurioli C, Romagnoli M, Poletti $\mathrm{V}$ : Transbronchial biopsy is useful in predicting UIP pattern.Respir Res 2012;13:96.

-3 Kaarteenaho R: The current position of surgical lung biopsy in the diagnosis of idiopathic pulmonary fibrosis. Respir Res 2013;14:43.

4 Nguyen W, Meyer KC: Surgical lung biopsy for the diagnosis of interstitial lung disease: a review of the literature and recommendations for optimizing safety and efficacy. Sarcoidosis Vasc Diffuse Lung Dis 2013;30:3-16.

5 Maguire MF, Ravenscroft A, Beggs D, Duffy IP: A questionnaire study investigating the prevalence of the neuropathic component of chronic pain after thoracic surgery. Eur J Cardiothorac Surg 2006;29:800-805. 
6 Fibla JJ, Molins L, Blanco A, et al: Video-assisted thoracoscopic lung biopsy in the diagnosis of interstitial lung disease: a prospective, multicenter study in 224 patients. Arch Bronchoneumol 2012;48:81-85.

$>7$ Poletti V, Casoni GL, Gurioli C, Ryu JH, Tomassetti S: Lung cryobiopsies: a paradigm shift in diagnostic bronchoscopy? Respirology 2014;19:645-654.

-8 Poletti V, Benzaquen S: Transbronchial cryobiopsy in diffuse parenchymal lung disease. A new star in the horizon. Sarcoidosis Vasc Diffuse Lung Dis 2014;31:178-181.

$>9$ Schuhmann M, Bostanci K, Bugalho A, Warth A, Schnabel PA, Herth FJ, Eberhardt R: Endobronchial ultrasound-guided cryobiopsies in peripheral pulmonary lesions: a feasibility study. Eur Respir J 2014,43:233-239.

10 Babiak A, Hetzel J, Krishna G, Fritz P, Moeller P, Balli T, Hetzel M: Transbronchial cryobiopsy: a new tool for lung biopsies. Respiration 2009;78:203-208.

11 Pajares V, Torrego A, Puzo C, Lerma E, Gil De Bernabé MA, Franquet T: Transbronchial lung biopsy using cryoprobes (in Spanish). Arch Bronconeumol 2010;46:111-115.

12 Griff S, Ammenwerth W, Schönfeld N, Bauer TT, Mairinger T, Blum TG, Kollmeier J, Grüning W: Morphometrical analysis of transbronchial cryobiopsies. Diagn Pathol 2011;6:53.
13 Kropski JA, Pritchett JM, Mason WR, Sivarajan L, Gleaves LA, Johnson JE, Lancaster LH, Lawson WE, Blackwell TS, Steele MP, Loyd JE, Rickman OB: Bronchoscopic cryobiopsy for the diagnosis of diffuse parenchymal lung disease. PLoS One 2013;12:e78674.

14 Yarmus L, Akulian J, Gilbert C, Illei P, Shah P, Merlo C, Orens J, Feller-Kopman D: Cryoprobe transbronchial lung biopsy in patients after lung transplantation: a pilot safety study. Chest 2013;143:621-626.

15 Fruchter O, Fridel L, Rosengarten D, et al: Transbronchial cryo-biopsy in lung transplantation patients: first report. Respirology 2013;18:669-673.

16 Fruchter O, Fridel L, Rosengarten D, et al: Transbronchial cryobiopsy in immunocompromised patients with pulmonary infiltrates: a pilot study. Lung 2013;191:619-624.

-17 Fruchter O, Fridel L, El Raouf BA, AbdelRahman N, Rosengarten D, Kramer MR: Histological diagnosis of interstitial lung diseases by cryo-transbronchial biopsy. Respirology 2014; 19:683-688.

$>18$ Casoni GL, Tomassetti S, Cavazza A, et al: Transbronchial lung cryobiopsy in the diagnosis of fibrotic interstitial lung diseases. PLoS One 2014;9:e86716.

19 Pajares V, Puzo C, Castillo D, Lerma E, Montero MA, Ramos-Barbón D, Amor-Carro O, Gil de Bernabé A, Franquet T, Plaza V, Hetzel J, Sanchis J, Torrego A: Diagnostic yield of transbronchial cryobiopsy in interstitial lung disease: a randomized trial. Respirology 2014; 19:900-906.
20 Griff S, Schönfeld N, Ammenwerth W, Blum TG, Grah C, Bauer TT, Grüning W, Mairinger T, Wurps H: Diagnostic yield of transbronchial cryobiopsy in non-neoplastic lung disease: a retrospective case series. BMC Pulm Med 2014;14:171.

21 Hernández-González F, Lucena CM, Ramírez J, Sánchez M, Jimenez MJ, Xaubet A, Sellares J, Agustí C: Cryobiopsy in the diagnosis of diffuse interstitial lung disease: yield and costeffectiveness analysis. Arch Bronconeumol 2015;51:261-267.

22 Gershman E, Fruchter O, Benjamin F, Nader AR, Rosengarten D, Rusanov V, Fridel L, Kramer MR: Safety of cryo-transbronchial biopsy in diffuse lung diseases: analysis of three hundred cases. Respiration 2015;90:40-46.

23 Hagmeyer L, Theegarten D, Wohlschläger J, Treml M, Matthes S, Priegnitz C, Randerath WJ: The role of transbronchial cryobiopsy and surgical lung biopsy in the diagnostic algorithm of interstitial lung disease. Clin Respir J 2015, Epub ahead of print.

24 Reif F: Simple applications of macroscopic thermodynamics; in Condon EU (ed): Mc Graw Hill Series: Fundamentals of Statistical and Thermal Physics. Colorado, Waveland Press, 2008, pp 152-190.

25 Franke KJ, Szyrach M, Nilius G, Hetzel J, Hetzel M, Ruehle KH, Enderle MD: Experimental study on biopsy sampling using new flexible cryoprobes: influence of activation time, probe size, tissue consistency, and contact pressure of the probe on the size of the biopsy specimen. Lung 2009;187:253-559. 